\title{
Reactivity of Cyclic Imino Ether Salts Having Vinyl Group V. Spontaneous and Base-Catalyzed Polymerization of $N$-Protio Salts of 2-Alkenyl-2-oxazolines and 2-Alkenyl-5,6-dihydro-4H-1,3-oxazines
}

Dedicated to the Memory of the late Professor Ichiro Sakurada

\author{
Masatoshi MiYamoto, Yoshiyuki SANO, ${ }^{* 1}$ and Takeo SAEGUSA*2 \\ Department of Synthetic Chemistry, Faculty of Engineering, \\ Kyoto University, Kyoto 606, Japan \\ ${ }^{* 1}$ Department of Industrial Chemistry, Shiga Prefectural Junior College, \\ Hikone 522, Japan
}

(Received January 29, 1987)

\begin{abstract}
Four derivatives of 2-alkenyl cyclic imino ethers were reacted with fluorosulfonic and with trifluoromethanesulfonic acids. 2-Isopropenyl-2-oxazoline (1b) and 2-isopropenyl-5,6dihydro-4H-1,3-oxazine (1d) formed the stable $N$-protonated salts at $0^{\circ} \mathrm{C}$. Whereas, 2-vinyl-2oxazoline (1a) and 2-vinyl-5,6-dihydro-4H-1,3-oxazine (1c) were polymerized on protonation (spontaneous polymerization) at the same temperature to give polymers consisting of two kinds of units; one was formed by the opening of vinyl group and the other was derived by a proton transfer. By a low temperature reaction of 1 a with fluorosulfonic acid at $-20^{\circ} \mathrm{C}$, the $N$-protonated salt was successfully isolated, but the corresponding salt of 1c was not obtained by the same procedure. For these three salts isolated, base-catalyzed polymerization was examined with pyridine and triethylamine as initiators at a temperature below $20^{\circ} \mathrm{C}$. The salt of $1 \mathrm{~b}$ gave a polymer consisting exclusively of the proton transferred unit. On the contrary, the salt of 1d was not polymerized at all. As a reference salt, the $N$-methyl salt of 1d, i.e., 3-methyl-2-isopropenyl-5,6-dihydro- $4 H-1,3-$ oxazinium salt, was prepared by the reaction of $1 \mathrm{~d}$ with methyl trifluoromethanesulfonate, which was not polymerized, too. On the basis of these findings the reactivity of $N$-methyl and $N$-protio salts of 2-alkenyl cyclic imino ethers were discussed.
\end{abstract}

KEY WORDS Cyclic Imino Ethers / Super Acids / 2-Alkenyl-2-oxazolinium Salt / $N$-Protio-2-alkenyl-5,6-dihydro-4 $H$-1,3-oxazinium Salt / ProtonTransfer Polymerization / Steric Effect /

Cyclic imino ethers with 2-vinyl and 2isopropenyl substituents have been know to be polymerized by various patterns to give different types of polymers (Scheme 1). Recently we have demonstrated the "spontaneous" mode of polymerization for 2-vinyl-2oxazoline (1a) ${ }^{1}$ and 2-vinyl-5,6-dihydro-4 $H$ 1,3-oxazine $(1 \mathrm{c})^{2}$ on $N$-alkylation with Meerwein reagents and super acid esters (eq 4). Whereas, the reaction of 2-isopropenyl-2oxazoline (1b) with those alkylating agents formed the corresponding stable $N$-alkyl salts, for which base-catalyzed polymerization as well as radical polymerization and copolymerization were studied (eq 5). ${ }^{3}$

In the "spontaneous" polymerization, $N$ alkyl salts of 2-alkenyl oxazolines and oxazines are once formed, which function as the monomer, and their reactivities depend on the ring size of the imino ether cycles and the substituents on the olefinic group. On the other hand, Tomalia et al. reported the interesting ring-preserved polymerization using $N$-protio-2-isopropenyl-2-oxazolinium

*2 To whom inquires about the paper should be addressed. 
salt (8b) (eq 2), ${ }^{4}$ which has a close similarity ethers have not been reported and, therefore, to the $N$-methyl salt. However, the $N$-proton- their general reactivities have not been known. ated salts of other 2-alkenyl cyclic imino

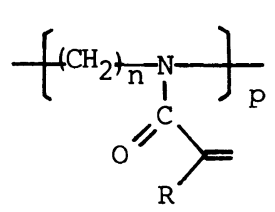

2

(for $n=2, R=M e)$
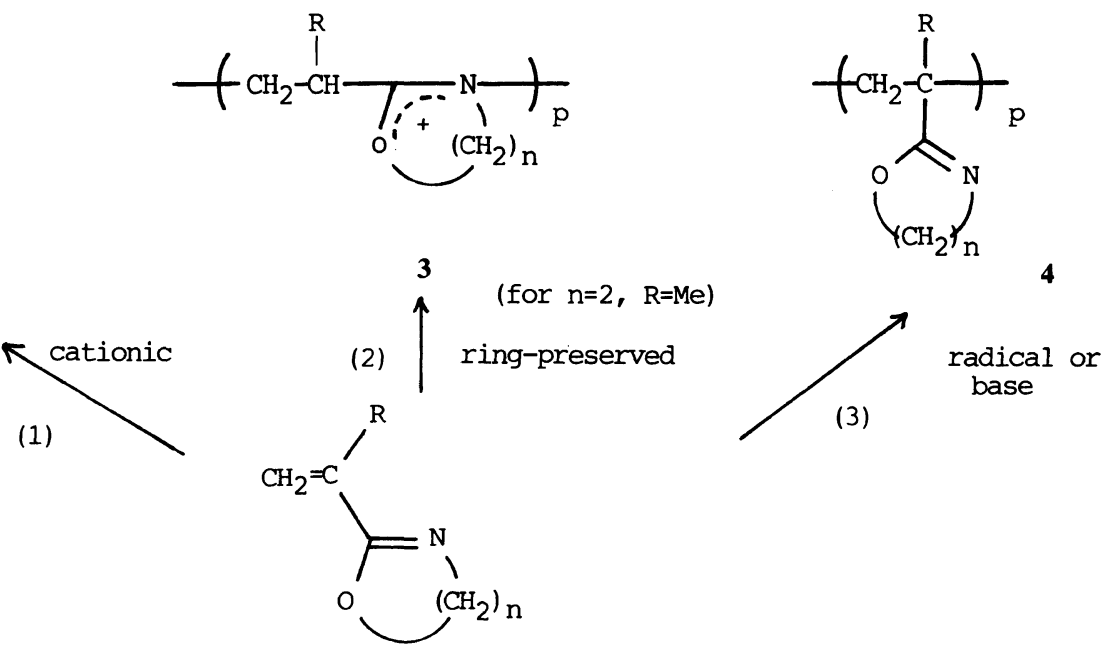

(3)
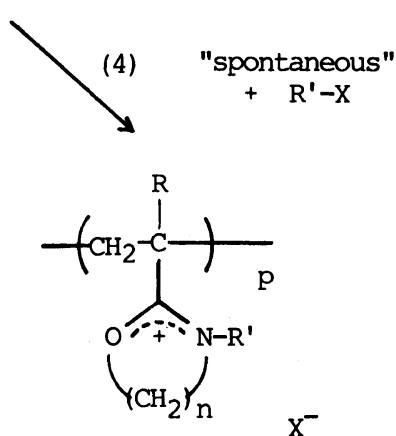

6a, $n=2, \mathrm{R}=\mathrm{H}$

6b, $n=2, \mathrm{R}=\mathrm{Me}$

6c, $n=3, \mathrm{R}=\mathrm{H}$

Scheme 1.

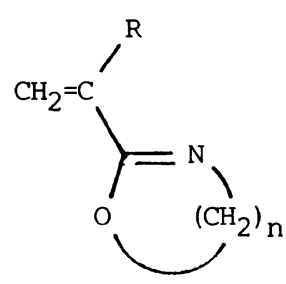

7a, $\mathrm{X}=\mathrm{FSO}_{3}$

7b, $\mathrm{X}=\mathrm{CF}_{3} \mathrm{SO}_{3}$

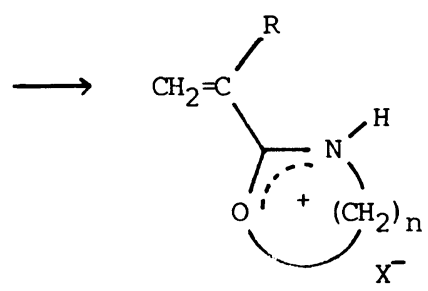

(TfO)

8a, $n=2, \mathrm{R}=\mathrm{H}$

$\mathbf{8 b}, n=2, \mathrm{R}=\mathrm{Me}$

(8c), $n=3, \mathrm{R}=\mathrm{H}$

8d, $n=3, \mathrm{R}=\mathrm{Me}$

Scheme 2. 
The present paper reports the reactions of 2alkenyl-2-oxazolines and -5,6-dihydro-4H-1,3oxazines, 1a-d, with super acids which bring about "spontaneous" polymerization or the formation of the $N$-protonated salts 8 . Then, the base-catalyzed polymerization of the once isolated $N$-protonated salts involving proton transfer is described. In addition, the preparation and reaction of $N$-methyl-2-isopropenyl5,6-dihydro-4H-1,3-oxazinium salt (5d) are reported, too, which constitute an extension of our studies on $N$-methyl salts of 2-vinylic derivatives of 2-oxazoline. Based on these results the reactivities of $N$-methyl and $N$-protio salts of the series of cyclic imino ethers are compared.

\section{EXPERIMENTAL}

\section{Materials}

Cyclic imino ethers $\mathbf{1 a - d}$ were prepared as previously reported, ${ }^{1,2,4}$ and purified by repeated distillations at a reduced pressure. Fluorosulfonic (7a) and trifluoromethanesulfonic acids (7b) were commercial reagents, which were used without further purification. Methyl trifluoromethanesulfonate was prepared by the reaction of $7 \mathbf{b}$ with dimethyl sulfate..$^{5}$ Other reagents and solvents were supplied commercially and purified by distillation.

\section{Instrumentation}

${ }^{1} \mathrm{H}$ NMR spectra were recorded on a Hitachi R-20B spectrometer operating at $60 \mathrm{MHz} .{ }^{13} \mathrm{C}$ NMR spectra were recorded on a Hitachi R-900 Fourier transform spectrometer operating at $22.6 \mathrm{MHz}$. IR spectra were recorded on a Hitachi 260-20 infrared spectrometer. Melting points were measured by DSC endotherms (Rigaku Thermoflex DSC, Japan) under nitrogen atmosphere.

\section{Preparation of $\mathbf{8}$}

A typical run carried out under a nitrogen atmosphere was as follows. To a vigorously stirred solution of $20 \mathrm{mmol}$ of 7 in $50 \mathrm{ml}$ of dichloromethane was added dropwise 10 mmol of 1 dissolved in $10 \mathrm{ml}$ of dichloromethane at $-30^{\circ} \mathrm{C}$. On every drop of 1 , a white product precipitated out. After the all of 1 was added, the product was collected by filtration, which was washed thoroughly with dichloromethane, and dried in vacuo.

8a: $\left(96^{\circ} \%\right.$ yield); mp $20-23^{\circ} \mathrm{C} ;{ }^{1} \mathrm{H}$ NMR $\left(\mathrm{CD}_{3} \mathrm{CN}\right) \delta 4.17\left(2 \mathrm{H}, \mathrm{t}, \mathrm{CH}_{2}-\mathrm{N}\right), 5.05(2 \mathrm{H}, \mathrm{t}$, $\left.\mathrm{CH}_{2}-\mathrm{O}\right), 6.49(1 \mathrm{H}, \mathrm{m}, \mathrm{C}=\mathrm{CH}$ trans $), 6.63(1 \mathrm{H}$, $\mathrm{m}, \mathrm{C}=\mathrm{CH}$ gem $)$, and $6.72 \mathrm{ppm}(1 \mathrm{H}, \mathrm{m}, \mathrm{C}=$ $\mathrm{CH}$ cis $) ;{ }^{13} \mathrm{C}-\mathrm{NMR}\left(\mathrm{CD}_{3} \mathrm{CN}\right) \delta 45.70\left(\mathrm{C}_{4}\right)$, $73.82\left(\mathrm{C}_{5}\right), 118.17\left(\mathrm{C}_{\alpha}\right), 139.51\left(\mathrm{C}_{\beta}\right)$, and 176.70 ppm $\left(\mathrm{C}_{2}\right)$; IR (acetonitrile) $1652\left(v_{\mathrm{C}=\mathrm{N}}\right), 1609$ $\left(v_{\mathrm{C}=\mathrm{C}}\right), 1290,1072,720$, and $575 \mathrm{~cm}^{-1}$. Anal. Calcd for $\mathrm{C}_{5} \mathrm{H}_{8} \mathrm{NO}_{4} \mathrm{FS} \cdot 0.3 \mathrm{H}_{2} \mathrm{O}$ (hygroscopic): . C, $29.62 \%$; H, 4.28\% $\mathrm{N}, 6.91 \%$. Found: C, $29.58 \%$; H, $4.56 \%$; N, $6.65 \%$.

8b: $\left(91 \%\right.$ yield); white solid; $\mathrm{mp} 48^{\circ} \mathrm{C} ;{ }^{1} \mathrm{H}$ NMR $\left(\mathrm{CD}_{3} \mathrm{CN}\right) \delta 2.01(3 \mathrm{H}, \mathrm{t}, \mathrm{Me}-\mathrm{C}), 4.33$ $\left(2 \mathrm{H}, \mathrm{t}, \mathrm{CH}_{2}-\mathrm{N}\right), 5.23\left(2 \mathrm{H}, \mathrm{t}, \mathrm{CH}_{2}-\mathrm{O}\right), 6.14$ $(1 \mathrm{H}, \mathrm{m}, \mathrm{C}=\mathrm{CH} c i s)$, and $6.39 \mathrm{ppm}(1 \mathrm{H}, \mathrm{m}$, $\mathrm{C}=\mathrm{CH}$ trans $) ;{ }^{13} \mathrm{C}$ NMR $\left(\mathrm{CD}_{3} \mathrm{CN}\right) \delta 17.22$ $(\mathrm{Me}-\mathrm{C}=\mathrm{C}), 45.69\left(\mathrm{C}_{4}\right), 73.08\left(\mathrm{C}_{5}\right), 127.32$ $\left(\mathrm{C}_{\alpha}\right), 133.18\left(\mathrm{C}_{\beta}\right)$, and $167.20 \mathrm{ppm}\left(\mathrm{C}_{2}\right)$; IR (acetonitrile) $1658\left(v_{\mathrm{C}=\mathrm{N}}\right), 1615\left(v_{\mathrm{C}=\mathrm{C}}\right), 1280$, 1196, and $712 \mathrm{~cm}^{-1}$. Anal. Calcd for $\mathrm{C}_{6} \mathrm{H}_{10} \mathrm{NO}_{4} \mathrm{FS} \cdot 0.2 \mathrm{H}_{2} \mathrm{O}: \mathrm{C}, 33.55 \%$; H, $4.88 \%$; $\mathrm{N}, 6.52 \%$. Found: C, $33.49 \%$; H, $5.08 \%$; N, $6.24 \%$.

$\mathbf{8 c}$ could not be isolated in pure form, but obtained as a mixture with $9 c$. The formation of $8 \mathbf{c}$ was confirmed from ${ }^{1} \mathrm{H}$ NMR spectrum of the mixture; ${ }^{1} \mathrm{H}$ NMR $\left(\left(\mathrm{CD}_{3}\right)_{2} \mathrm{SO}\right) \delta 1.8-$ $2.5\left(\mathrm{CH}_{2}-\mathrm{CH}\right.$ of $\mathrm{A}$ unit of $9 \mathrm{c}$ and $\left.-\mathrm{C}-\mathrm{CH}_{2}-\mathrm{C}\right)$, 2.7-3.0 $\left(\mathrm{CH}_{2} \mathrm{CH}\right.$ of $\mathrm{A}$ unit and $\mathrm{CH}_{2}-\mathrm{C}=\mathrm{N}$ of $\mathrm{B}$ unit of 9c), 3.1-3.8 (N-CH $-\mathrm{C}-\mathrm{C}$ of B unit of $9 \mathrm{c}$ and $\left.\mathrm{N}-\mathrm{CH}_{2}-\mathrm{C}-\mathrm{O}\right), 4.5-5.5\left(\mathrm{CH}_{2}-\mathrm{O}\right)$, $6.3-6.7\left(\mathrm{CH}_{2}=\mathrm{CH}\right.$ of $\left.8 \mathrm{c}\right)$, and $10-11 \mathrm{ppm}$ (NH of A unit).

8d: ( $94 \%$ yield); white solid without critical $\mathrm{mp} ;{ }^{1} \mathrm{H}$ NMR $\left(\mathrm{CD}_{3} \mathrm{CN}\right) \delta 2.01(3 \mathrm{H}, \mathrm{t}, \mathrm{Me}-\mathrm{C})$, $2.07-2.38\left(2 \mathrm{H}, \mathrm{m}, \mathrm{C}-\mathrm{CH}_{2}-\mathrm{C}\right), 3.61(2 \mathrm{H}, \mathrm{t}$, $\left.\mathrm{CH}_{2}-\mathrm{N}\right), 4.72\left(2 \mathrm{H}, \mathrm{t}, \mathrm{CH}_{2}-\mathrm{O}\right), 6.00(1 \mathrm{H}, \mathrm{m}$, $\mathrm{C}=\mathrm{CH}$ cis $), 6.20(1 \mathrm{H}, \mathrm{m}, \mathrm{C}=\mathrm{CH}$ trans $) ;{ }^{13} \mathrm{C}$ 
NMR $\left(\mathrm{CD}_{3} \mathrm{CN}\right) \delta 16.99(\mathrm{Me}-\mathrm{C}=\mathrm{C}), 18.06$ $\left(\mathrm{C}_{5}\right), 38.25\left(\mathrm{C}_{4}\right), 69.58\left(\mathrm{C}_{6}\right), 128.95\left(\mathrm{C}_{\alpha}\right), 132.46$ $\left(\mathrm{C}_{\beta}\right), 168.28\left(\mathrm{C}_{2}\right)$; IR (Nujol) 3245 and 3215 $\left(v_{\mathrm{N}-\mathrm{H}}\right), 1661\left(v_{\mathrm{C}=\mathrm{N}}\right), 1617\left(v_{\mathrm{C}=\mathrm{C}}\right), 1505,1235$, 1150, 1028, and $622 \mathrm{~cm}^{-1}$. Anal. Calcd for $\mathrm{C}_{8} \mathrm{H}_{12} \mathrm{NO}_{4} \mathrm{~F}_{3} \mathrm{~S}: \mathrm{C}, 34.91 \% ; \mathrm{H}, 4.39 \% ; \mathrm{N}$, $5.09 \%$; N, $5.09 \%$. Found: C, $34.76 \%$; $4.51 \%$; N, $4.84 \%$.

\section{General Procedure of "Spontaneous" Polym- erization of 1 upon Protonation}

The reaction was carried out by the same procedure as the above preparation of 8 . The product was characterized as follows.

9a: 94\% yield; white hygroscopic solid; ${ }^{1} \mathrm{H}$ $\mathrm{NMR}\left(\left(\mathrm{CD}_{3}\right)_{2} \mathrm{SO}\right) \delta 1.8-2.6\left(\mathrm{CH}_{2}-\mathrm{CH}\right.$ of $\mathrm{A}$ unit), 2.7-3.2 $\left(\mathrm{CH}_{2}-\mathrm{CH}\right.$ of $\mathrm{A}$ unit and $\mathrm{CH}_{2}-$ $\mathrm{C}=\mathrm{N}$ of $\mathrm{B}$ unit)), 3.2-3.7 ( $\mathrm{N}-\mathrm{CH}_{2}-\mathrm{C}-\mathrm{C}$ of $\mathrm{B}$ unit), 3.7-4.5 (N-CH $-\mathrm{C}-\mathrm{O}), 4.6-5.2\left(\mathrm{CH}_{2}-\right.$ $\mathrm{O})$, and $11-12.8 \mathrm{ppm}$ ( $\mathrm{NH}$ of $\mathrm{A}$ unit); IR (Nujol) $1640\left(v_{\mathrm{C}=\mathrm{N}}\right), 1230,1155,1023$, and 564 $\mathrm{cm}^{-1}$. Anal. Calcd for $\mathrm{C}_{5} \mathrm{H}_{8} \mathrm{NO}_{4} \mathrm{FS} \cdot 0.2 \mathrm{H}_{2} \mathrm{O}$ : C, $29.91 \%$; H, $4.22 \%$; N, $6.98 \%$. Found: C, $29.87 \%$; H, $4.16 \%$; N, $7.22 \%$.

9c: $95 \%$ yield; white hygroscopic solid; ${ }^{1} \mathrm{H}$ NMR $\left(\left(\mathrm{CD}_{3}\right)_{2} \mathrm{SO}\right) \delta 1.6-2.6\left(\mathrm{CH}_{2}-\mathrm{CH}\right.$ of $\mathrm{A}$ unit and $\left.-\mathrm{C}-\mathrm{CH}_{2}-\mathrm{C}\right), 2.7-3.0\left(\mathrm{CH}_{2}-\mathrm{CH}\right.$ of $\mathrm{A}$ unit and $\mathrm{CH}_{2}-\mathrm{C}=\mathrm{N}$ of $\mathrm{B}$ unit), 3.2-3.9 (N$\mathrm{CH}_{2}-\mathrm{C}-\mathrm{C}$ of $\mathrm{B}$ unit and $\left.\mathrm{N}-\mathrm{CH}_{2}-\mathrm{C}-\mathrm{O}\right), 4.5-$ $5.5\left(\mathrm{CH}_{2}-\mathrm{O}\right)$, and $7-8 \mathrm{ppm}$ ( $\mathrm{NH}$ of $\mathrm{A}$ unit). IR (Nujol) $1650\left(v_{\mathrm{C}=\mathrm{N}}\right), 1260,1155$, and $625 \mathrm{~cm}^{-1}$.

\section{General Procedure of Base-Catalyzed Polym- erization of $\mathbf{8}$}

Into a stirred solution of $3 \mathrm{mmol}$ of 8 in $2 \mathrm{ml}$ of $N, N$-dimethylformamide (DMF), 0.06 mmol of pyridine was added at $-20^{\circ} \mathrm{C}$ under nitrogen. The solution was then maintained at $0^{\circ} \mathrm{C}$ for $10 \mathrm{~h}$. After the reaction, the mixture was poured into $50 \mathrm{ml}$ of a mixture of dichloromethane and acetonitrile $(1: 1$ by vol) to precipitate the polymeric product. The precipitated product was then purified by repeated reprecipitation from DMF (solvent) to the above mixture (nonsolvent), washed with dichloromethane and dried in vacuo. The characterizations of the product are as follows.

9a: its ${ }^{1} \mathrm{H}$ NMR and IR spectra are essentially the same as those of the spontaneous polymer.

9b: white hygroscopic solid; ${ }^{1} \mathrm{H}$ NMR $\left(\left(\mathrm{CD}_{3}\right)_{2} \mathrm{SO}\right) \delta 1.0-1.6\left(3 \mathrm{H}, \mathrm{CH}_{3}-\mathrm{C}\right), 2.8-3.6$ $\left(3 \mathrm{H}, \mathrm{CH}\right.$, and $\left.\mathrm{N}-\mathrm{CH}_{2}-\mathrm{C}-\mathrm{C}\right), 3.7-4.5(\mathrm{~N}-$ $\left.\mathrm{CH}_{2}-\mathrm{C}-\mathrm{O}\right)$, and $4.5-5.3 \mathrm{ppm}\left(\mathrm{CH}_{2}-\mathrm{O}\right)$; IR (Nujol) $1643\left(v_{\mathrm{C}=\mathrm{N}}\right), 1285,1158,718$, and 560 $\mathrm{cm}^{-1}$. Anal. Calcd for $\mathrm{C}_{6} \mathrm{H}_{10} \mathrm{NO}_{4} \mathrm{FS} \cdot 0.3 \mathrm{H}_{2} \mathrm{O}$ : C, $33.27 \%$; H, $4.93 \%$; N, 6.47\%. Found: C, $33.18 \%$; H, $5.14 \%$; N, $6.82 \%$.

\section{Preparation of $\mathbf{5 d}$}

1d was reacted with methyl trifluoromethanesulfonate in diethyl ether, as described in the preparation of $\mathbf{5 b}$. The product was isolated as colorless liquid in $87 \%$ yield:

5d: liquid; ${ }^{1} \mathrm{H}$ NMR $\left(\mathrm{CD}_{3} \mathrm{CN}\right) \delta 2.01(3 \mathrm{H}, \mathrm{t}$, $\mathrm{Me}-\mathrm{C}), 2.07-2.38\left(2 \mathrm{H}, \mathrm{m}, \mathrm{C}-\mathrm{CH}_{2}-\mathrm{C}\right), 3.35$ $(3 \mathrm{H}, \mathrm{s}, \mathrm{N}-\mathrm{Me}), 3.70\left(2 \mathrm{H}, \mathrm{t}, \mathrm{CH}_{2}-\mathrm{N}\right), 4.63(2 \mathrm{H}$, $\left.\mathrm{t}, \mathrm{CH}_{2}-\mathrm{O}\right), 5.67-5.72(1 \mathrm{H}, \mathrm{m}, \mathrm{C}=\mathrm{CH}$ trans $)$, and $5.76-5.85 \mathrm{ppm}(1 \mathrm{H}, \mathrm{m}, \mathrm{C}=\mathrm{CH}$ cis $) ;{ }^{13} \mathrm{C}$ NMR $\left(\mathrm{CD}_{3} \mathrm{CN}\right) \delta 18.50(\mathrm{Me}-\mathrm{C}=\mathrm{C}), 19.57$ $\left(\mathrm{C}_{5}\right), 42.86(\mathrm{Me}-\mathrm{N}), 48.30\left(\mathrm{C}_{4}\right), .69 .56\left(\mathrm{C}_{6}\right)$, $126.64\left(\mathrm{C}_{\beta}\right)$, and $133.43 \mathrm{ppm}\left(\mathrm{C}_{\alpha}\right)$; IR (neat) $2920,1648\left(v_{\mathrm{C}=\mathrm{N}}\right), 1475,1420,1304,1250$ $\left(v_{\mathrm{S}=\mathrm{o}}\right), 1217,1142,1022$, and $618 \mathrm{~cm}^{-1}$, Anal. Calcd for $\mathrm{C}_{9} \mathrm{H}_{14} \mathrm{NO}_{4} \mathrm{~F}_{3} \mathrm{~S}$ : C, $37.37 \%$; $\mathrm{H}, 4.88 \%$; N, $4.84 \%$. Found: C, $37.04 \%$; $\mathrm{H}, 4.82 \%$; N, $5.05 \%$.

\section{RESULTS AND DISCUSSION}

\section{Reactions of 2-Alkenyl Cyclic Imino Ethers with Super Acids}

The oxazoline derivatives $\mathbf{1 a}$ and $\mathbf{1 b}$ were reacted with fluorosulfonic acid (7a) and the oxazine derivatives $1 \mathrm{c}$ and $\mathbf{1 d}$ were reacted with trifluoromethanesulfonic acid (7b). Both acids are considered to have a similar reactivity with cyclic imino ethers, and the reactivities of the product salts are influenced little by the counterions which are essentially non-nucleophilic. The results of the reactions 
Reactivity of Cyclic Imino Ether Salts Having Vinyl Group V.

Table I. Protonation of 2-vinylic derivatives of cyclic imino ethers with super acids ${ }^{a}$

\begin{tabular}{|c|c|c|c|c|c|c|c|c|c|c|c|}
\hline \multirow{4}{*}{$\begin{array}{l}\text { Run } \\
\text { No. }\end{array}$} & \multirow{4}{*}{$\begin{array}{c}\text { Imino } \\
\text { ether } \\
1\end{array}$} & \multicolumn{2}{|c|}{ Acid } & \multirow{4}{*}{$\frac{\text { Temp. }}{{ }^{\circ} \mathrm{C}}$} & \multicolumn{7}{|c|}{ Product } \\
\hline & & \multirow{3}{*}{ Structure } & \multirow{3}{*}{$\begin{array}{l}\text { Molar } \\
\text { ratio } \\
\text { to } 1\end{array}$} & & \multicolumn{3}{|c|}{ Protonated salt $\mathbf{8}$} & \multicolumn{4}{|c|}{ Spontaneous polymer 9} \\
\hline & & & & & \multirow{2}{*}{ Structure } & Yield & $\mathrm{Mp}^{\mathrm{b}}$ & \multirow{2}{*}{ Structure } & \multirow{2}{*}{$\frac{\text { Yield }}{\%}$} & \multirow{2}{*}{$\begin{array}{c}\text { Unit ratio }^{c} \\
\text { A/B }\end{array}$} & \multirow{2}{*}{$\frac{\eta_{\mathrm{sp}} / c^{\mathrm{d}}}{\mathrm{dlg}^{-1}}$} \\
\hline & & & & & & $\%$ & $\overline{{ }^{\circ} \mathrm{C}}$ & & & & \\
\hline 1 & $1 \mathbf{a}$ & $7 a$ & 2.0 & -30 & $\mathbf{8 a}$ & 96 & $20-23$ & - & - & - & - \\
\hline 2 & $1 \mathbf{a}$ & $7 \mathbf{a}$ & 1.2 & 0 & - & - & - & $9 a$ & 94 & $0.25 / 1$ & 0.027 \\
\hline 3 & $1 b$ & $7 a$ & 1.2 & 0 & $8 b$ & 91 & 48 & - & - & - & - \\
\hline 4 & 1c & $7 \mathbf{b}$ & 2.0 & -30 & $(8 c)$ & (61) & & $(9 c)$ & $(31)$ & n.d. & n.d. \\
\hline 5 & 1c & $7 \mathbf{b}$ & 1.2 & 0 & - & - & - & $9 c$ & 95 & $0.32 / 1$ & 0.031 \\
\hline 6 & 1d & $7 \mathbf{b}$ & 1.2 & 0 & $8 d$ & 94 & e & - & - & - & - \\
\hline
\end{tabular}

a Protonation was carried out in dichloromethane.

b Determined from DSC endotherms under nitrogen.

c Ratio of vinyl polymerized unit (A) to proton transferred one (B) determined by the ${ }^{1} \mathrm{H}$ NMR spectra.

d $c=0.12 \mathrm{dlg}^{-1}$, in DMF containing $2 \mathrm{wt} \%$ of $\mathrm{NaBF}_{4}$.

e No critical melting point was observed.

are summarized in Table I. In all runs the monomer was carefully added to a solution of the acid in dichloromethane with keeping the temperature at below $0^{\circ} \mathrm{C}$, and the product precipitated out immediately upon protonation. When isopropenyl derivatives $\mathbf{1 b}$ and 1d were reacted with a little excess of the acids at $0^{\circ} \mathrm{C}, N$-protio salts $8 \mathrm{~b}$ and $8 \mathrm{~d}$ were formed in high yields. $8 \mathrm{~b}$ was isolated as crystalline materials while 8d was a amorphous powder. In the case of 1a with a vinyl substituent the similar salt was formed as crystalline materials only when it was reacted at $-30^{\circ} \mathrm{C}$ with a large excess of 7a. By its reaction at $0^{\circ} \mathrm{C}$ with an about equimolar amount of 7a, a "spontaneous" polymerization predominated to give a polymer which was characterized as $9 \mathbf{a}$ (vide infra). For 1c, the spontaneous polymerization occurred quite readily on the protonation reaction to produce the similar polymers $9 \mathrm{c}$ in a high yield. Even at $-30^{\circ} \mathrm{C}$ the formation of polymer $9 \mathrm{c}$ was not avoided; a mixture of $\mathbf{8 c}$ and $9 \mathrm{c}$ at a ratio of $2: 1$ was obtained (determined by ${ }^{1} \mathrm{H}$ NMR; the signals at $\delta 6.3-6.7$ (vinyl group), 4.7, 3.7, and 2.2 (oxazinium group were assigned to $8 \mathrm{c}$ ). A trial to isolate $8 \mathrm{c}$ from the mixture was not successful, i.e., $8 \mathrm{c}$ was polymerized in the recrystallization procedure even in a strong acid medium.

The isolated salts, $\mathbf{8 a}, \mathbf{b}, \mathbf{d}$ were all wellcharacterized as indicated in the Experimental. They were soluble in aprotic polar solvents such as acetonitrile, DMF, and dimethyl sulfoxide (DMSO). However, the solutions turned to gel on standing at room temperature for a few days. These salts were also unstable in the solid state unlike the corresponding $\mathrm{N}$ methyl salts probably due to labile proton on nitrogen atom.

The structures of the polymers 9a and 9c produced by "spontaneous" polymerization on protonation were examined by IR and ${ }^{1} \mathrm{H}$ NMR (Experimental). The presence of oxazolinium ring in 9a was supported by the signals around $\delta 3.7-4.5\left(\mathrm{~N}-\mathrm{CH}_{2}\right), 4.6-5.3(\mathrm{O}-$ $\mathrm{CH}_{2}$ ), and $11-13 \mathrm{ppm}(\mathrm{NH})$. The additional signals appearing at $\delta 3.2-3.7 \mathrm{ppm}$ were reasonably assigned to the exo-cyclic $\mathrm{N}-\mathrm{CH}_{2}$, which indicated the unit derived by proton transfer. Thus, the polymer 9a consisted of both 2-(3-methyl-2-oxazolinium-2-yl)ethylene unit (A) and (2-oxazolinium-2,3-diylene) (ethylene) unit (B). The both units A and B in the polymer $9 \mathrm{c}$ were also supported by the 
signals at $\delta 7-8$ due to $\mathrm{N}-\mathrm{H}$ protons (A unit) and at $\delta 3.2-3.5$ due to the exo-cyclic $\mathrm{N}-\mathrm{CH}_{2}$ (B unit), respectively. The unit ratio $\mathrm{A} / \mathrm{B}$ was estimated from the integral ratio of $\mathrm{NH}$ proton

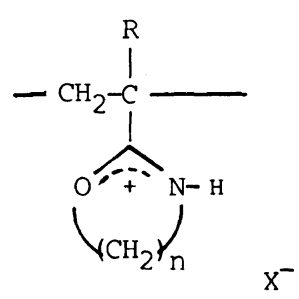

A

\section{Base-catalyzed Polymerization of $\mathbf{8}$}

The $N$-protonated salts $8 \mathbf{a}, \mathbf{8 b}$, and $\mathbf{8 c}$, were subjected to base-catalyzed polymerization as well as to radical polymerization. With azobisisobutyronitrile (AIBN) and benzoyl peroxide (BPO) as an initiator an unidentified gelled product was produced. It may probably due to the instability of these salts at a relatively higher reaction temperature. Basecatalyzed polymerizations with triethylamine to proton of onium ring (oxazolinium or oxazinium ring) (the second last column in Table I). In the both cases (Runs No. 2 and 5), the proportion of $\mathrm{B}$ is higher.

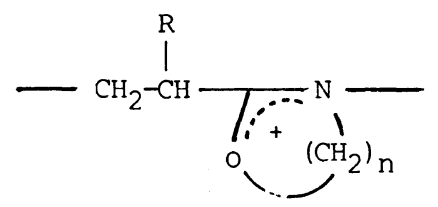

B

and pyridine as catalysts at $0^{\circ} \mathrm{C}, \mathbf{8 a}$ and $\mathbf{8 b}$ produced soluble polymeric products whereas the polymerization $8 \mathrm{~b}$ at $20^{\circ} \mathrm{C}$ gave a gelled product whose structure was not examined (Table II). The rate of polymerization of $\mathbf{8 a}$ was much faster than that of $\mathbf{8 b}$. The yield of the polymer of $\mathbf{8 a}$ was $98 \%$ after $1 \mathrm{~h}$ whereas that of $8 \mathrm{~b}$ was $54 \%$ after $10 \mathrm{~h}$. For the polymerization of $\mathbf{8 a}$, pyridine and triethylamine showed a similar catalytic activity. Con-
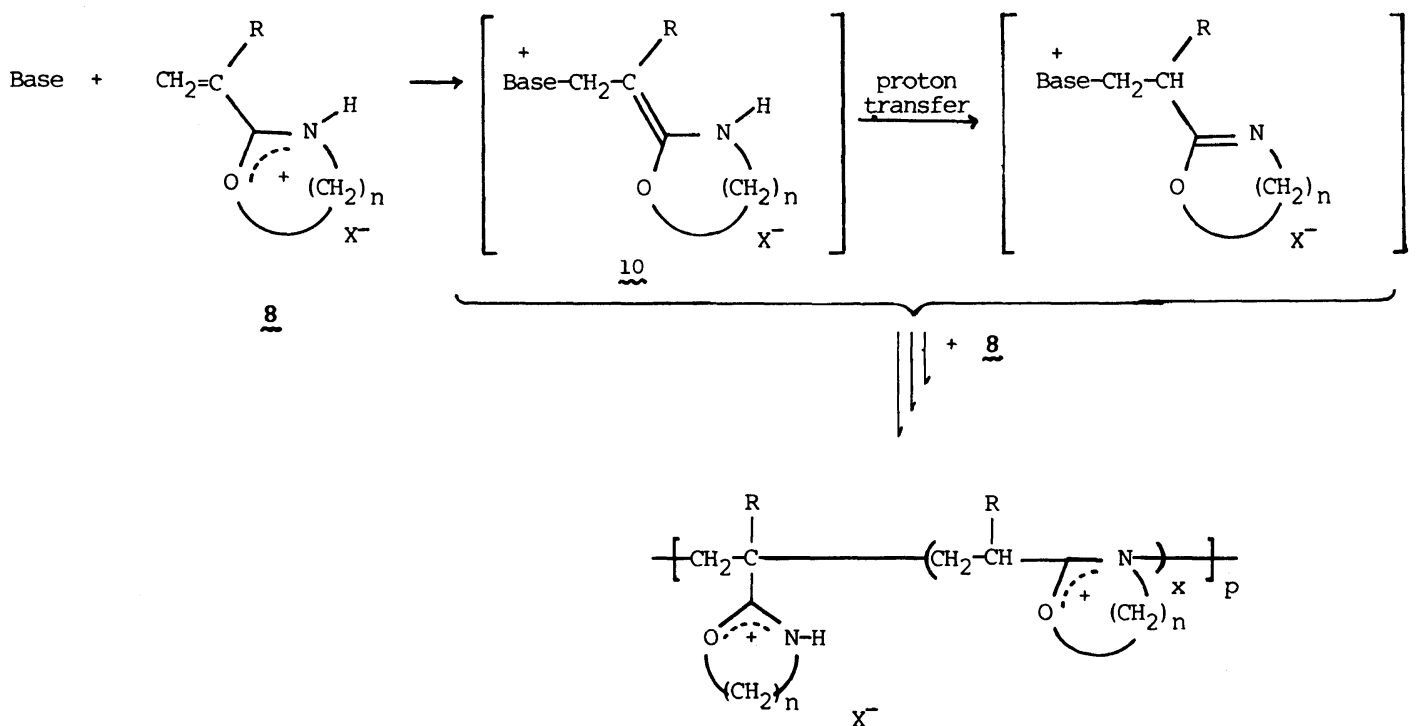

$$
\begin{aligned}
& \text { 9a, } n=2, \mathrm{R}=\mathrm{H} \\
& \text { 9b, } n=2, \mathrm{R}=\mathrm{Me} \\
& 9 \mathrm{c}, n=3, \mathrm{R}=\mathrm{H}
\end{aligned}
$$

Scheme 3. 
Reactivity of Cyclic Imino Ether Salts Having Vinyl Group V.

Table II. Base-catalyzed polymerization ${ }^{\mathrm{a}}$ of $\mathbf{8 a}$ and $\mathbf{8 b}$

\begin{tabular}{|c|c|c|c|c|c|c|c|}
\hline \multirow{3}{*}{$\begin{array}{l}\text { Run } \\
\text { No. }\end{array}$} & \multirow{3}{*}{8} & \multirow{3}{*}{ Catalyst $^{\mathrm{b}}$} & \multirow{3}{*}{$\frac{\text { Temp. }}{{ }^{\circ} \mathrm{C}}$} & \multirow{3}{*}{$\frac{\text { Time }}{\mathrm{h}}$} & \multicolumn{3}{|c|}{ Product } \\
\hline & & & & & Yield & \multirow{2}{*}{$\begin{array}{c}\text { Unit ratio }^{c} \\
\text { A/B }\end{array}$} & \multirow{2}{*}{$\frac{\eta_{\mathrm{sp}} / c^{\mathrm{d}}}{\mathrm{dl} \mathrm{g} \mathrm{g}^{-1}}$} \\
\hline & & & & & $\%$ & & \\
\hline 1 & $\mathbf{8 a}$ & Pyridine & 0 & 1 & 98 & $0.59 / 1$ & 0.042 \\
\hline 2 & $\mathbf{8 a}$ & $\mathrm{Et}_{3} \mathrm{~N}$ & 0 & 1 & 97 & $0.47 / 1$ & 0.038 \\
\hline 3 & $8 b$ & Pyridine & 0 & 10 & 54 & $0 \quad / 1$ & 0.033 \\
\hline 4 & $8 b$ & Pyridine & 20 & 50 & 87 & $0 \quad / 1$ & - $^{\mathrm{e}}$ \\
\hline
\end{tabular}

${ }^{\text {a }}$ In DMF.

b $2 \mathrm{~mol} \%$ to the monomer.

c Ratio of vinyl polymerized unit (A) with proton transferred one (B) analyzed by ${ }^{1} \mathrm{H}$ NMR spectroscopy.

d $c=0.12 \mathrm{dlg}^{-1}$, in DMF containing $2 \mathrm{wt} \%$ of $\mathrm{NaBF}_{4}$.

e A gelled product insoluble in DMF.

trarily, 8d was not polymerized below its decomposition temperature, i.e., $20^{\circ} \mathrm{C}$.

The structure of the product of the basecatalyzed polymerization of $\mathbf{8 a}$ was quite similar to that of the products of spontaneous polymerization upon protonation of 1a, but the unit ratio of A to B was higher in the basecatalyzed polymerization. The polymer of $\mathbf{8 b}$, on the other hand, was considered to consist exclusively of proton-transferred unit, i.e., poly[(2-oxazolinium-2,3-diylene)(ethylene)], because $\mathrm{NH}$ proton was not detected in the vicinity of $\delta 8-12$ in its ${ }^{1} \mathrm{H}$ NMR spectrum. In addition, the signals due to the ring-preserved unit were very similar to those of the oligomeric product of the ring-preserved polymerization reported by Tomalia et al. ${ }^{4}$

These polymers as well as the products of the "spontaneous" polymerization were not stable which were gelled at room temperature even under anhydrous conditions. They are soluble in DMF and DMSO, but insoluble in acetonitrile and other less-polar solvents. The inherent viscosities of DMF solutions containing $2 \mathrm{wt} \% \mathrm{NaBF}_{4}$ of the products of the basecatalyzed polymerization were in a range of $0.03-0.04$, which were slightly higher than those of the spontaneously produced ones. Judging from these viscosity numbers, the molecular weights of 9 were not high.
Although the mechanism for this interesting base-catalyzed polymerization has not been clarified, ketene-aminal $\mathbf{1 0}$ may reasonably be postulated as the active intermediate as in the case of the polymerization of $N$-methyl salt. This intermediate is to be formed by the addition of the catalyst base to the monomer, which participates in polymerization via two ways. One is the 1,4-addition to form the ordinary olefin-olefin linkage and the other is the proton transfer from nitrogen to the olefin carbon atom. The proton transfer process is followed by the addition of the ring nitrogen atom to the electron-deficient carbon to carbon double bond. Thus the ring structure is incorporated into the main chain of the product. In the spontaneous polymerization upon protonation the remaining free monomer functions as the catalyst base. An analogous proton transfer reaction has been reported in the spontaneous polymerization of 4-vinylpyridine with a strong Brønsted acid..$^{6,7}$

\section{Preparation and Polymerizability of 5d}

Prior to the general discussion on the reactivities of $N$-methyl and $N$-protio salts of 2alkenyl cyclic imino ethers, the reactivity of $\mathrm{N}$ methyl-2-isopropenyl-5,6-dihydro-4H-1,3oxazinium trifluoromethanesulfonate (5d) was examined, which was prepared by the reaction 
of 1d with methyl trifluoromethanesulfonate, without "spontaneous" polymerization. The product was isolated as colorless liquid, which was stable under an anhydrous condition in contrast to $\mathbf{8 d}$.

5d was subjected to radical polymerization with AIBN and BPO as an initiator. The reaction was carried out in DMF at temperatures as high as $100^{\circ} \mathrm{C}$ with various amounts of initiator, $0.5-5.0 \%$. However, no polymerization took place and the monomer $5 \mathbf{d}$ was recovered in all cases. The base-catalyzed polymerization of $\mathbf{5 d}$ was also examined in DMF with triethylamine and triphenylphosphine as a catalyst. At temperatures below $50^{\circ} \mathrm{C}$ no polymeric product was isolated. At $80^{\circ} \mathrm{C}$, a pale brown polymeric material was obtained in a yield of $\sim 30 \%$ whose structure was very complicated due to the concurrent ring-opening of oxazinium ring. With a stronger base such as sodium methoxide ( $3 \mathrm{~mol} \%$ ), a similar polymer of unidentified structure was produced even at room temperature.

5d was then subjected to radical copolymerization with methyl methacrylate (MMA), styrene (St), and $n$-butyl vinyl etehr (BVE) in the presence of $2 \mathrm{~mol} \%$ of AIBN. In the cases of MMA and St, only homopolymers of these comonomers were produced whose intrinsic viscosity was lower than $0.1 \mathrm{dl} \mathrm{g}^{-1}$ (in DMF). With BVE a dark brown precipitate was formed at room temperature which was considered as a charge transfer complex. However, this product was not polymerized by the prolonged heating at $80^{\circ} \mathrm{C}$.

From these results, $\mathbf{5 d}$ was shown to have neither polymerizability nor copolymerizability by both radical and base-catalyzed mechanisms.

\section{The General Polymerizabilities of 2-Alkenyl \\ Substituted Oxazolines and Oxazines and Their Salts}

For the series of 2-alkenyl cyclic imino ethers $1 \mathrm{a}-\mathbf{d}$ the radical or anionic olefinic polymerizations and the cationic ring-opening polymerizations have been known, as mentioned in the part of Introduction. In our studies, ${ }^{1-3,8}$ these monomers showed various patterns of reactions upon $\mathrm{N}$-alkylation and

Table III. Comparison of polymerizability of 1,5 , and 8

\begin{tabular}{|c|c|c|c|c|c|c|c|c|c|c|}
\hline \multirow{4}{*}{$\begin{array}{c}\text { Imino } \\
\text { ether } \\
1\end{array}$} & \multirow{2}{*}{\multicolumn{2}{|c|}{$\begin{array}{l}\text { Spontaneous } \\
\text { polymerization upon }\end{array}$}} & \multicolumn{6}{|c|}{$N$-methylated salt } & \multicolumn{2}{|c|}{$N$-protonated salt } \\
\hline & & & \multirow{3}{*}{$5(X)^{a}$} & \multicolumn{5}{|c|}{ Polymerizabilities } & \multirow{3}{*}{$8(X)^{a}$} & \multirow{3}{*}{$\begin{array}{l}\text { Polymeri- } \\
\text { zabilities by } \\
\text { base catalyst }\end{array}$} \\
\hline & \multirow[t]{2}{*}{ Alkylation } & \multirow[t]{2}{*}{ Protonation } & & \multirow[t]{2}{*}{$\begin{array}{c}\text { Base- } \\
\text { catalyzed }\end{array}$} & \multirow[t]{2}{*}{ Radical } & \multicolumn{3}{|c|}{$\begin{array}{c}\text { Radical } \\
\text { copolymerizability with }\end{array}$} & & \\
\hline & & & & & & MMA & St & BVE & & \\
\hline $1 \mathbf{a}$ & Yes & Yes & b & c & & & & & 8a $\left(\mathrm{FSO}_{3}\right)$ & High \\
\hline $\mathbf{1 b}$ & No & No & $\begin{array}{r}\mathbf{5 b}\left(\mathrm{BF}_{4}\right) \\
\left(\mathrm{FSO}_{3}\right)\end{array}$ & Low & Low & High & No & $\mathrm{No}^{\mathrm{d}}$ & $8 \mathrm{~b}\left(\mathrm{FSO}_{3}\right)$ & Moderate \\
\hline 1c & Yes & Yes & $\begin{array}{l}5 c(\mathrm{TfO}) \\
\left(\mathrm{FSO}_{3}\right)\end{array}$ & High & High & High & High & $\mathrm{High}^{\mathrm{e}}$ & b & c \\
\hline 1d & No & No & $5 d(\mathrm{TfO})$ & No & No & No & No & $\mathrm{No}^{\mathrm{c}}$ & 8d (TfO) & No \\
\hline
\end{tabular}

a The counter anion of the salt was shown in the parentheses.

b Not isolated.

c Probably high judging from the result of "spontaneous" polymerization.

d With isobutyl vinyl ether.

- With $n$-butyl vinyl ether. 
upon $N$-protonation (Table III). A summary is shown in the first part of Table III. In general, the monomers 1a and 1c with a vinyl group were polymerized upon both alkylation and protonation ("spontaneous" polymerization), whereas the monomers $\mathbf{1 b}$ and 1d with an isopropenyl group formed stable monomeric oxazolinium and oxazinium salts which were isolated without the disturbance by polymerization. These reactivities were not changed by types of the alkylating and protonating agents. Since "spontaneous" polymerizations occur via the transient monomers of $\mathrm{N}$-alkylated and $N$-protonated salts, the reactivity of the vinyl salts is considered to be much higher than that of isopropenyl salts. ${ }^{2}$ By the controlled reactions of 1a and 1c, however, the $N$-alkyl salt $\mathbf{5 c}$ and the $N$-protio salt $8 \mathbf{a}$ were isolated, but the similar salts $5 \mathbf{a}$ and $\mathbf{8 c}$ were not obtained in the discrete form. These results may be explained by two factors, i.e., the nucleophilicities of $1 \mathbf{a}$ and $1 \mathbf{c}$ which control the initiating abilities for the "spontaneous" polymerization, and the polymerization reactivities of the salts themselves. Since the nucleophilicity of imino group of oxazines is known to have about tentimes as high as that of oxazolines, ${ }^{9}$ the rate of alkylation of 1c is assumed to be much faster than that of 1a. Therefore, alkylation of 1c can be completed in the presence of an excess amount of alkylating agent before the free monomers initiate the polymerization. For 1a the rate is slower and the remaining free monomer reacts with the salt $\mathbf{5 a}$ to occur "spontaneous" polymerization. In the protonation reaction the salt formation was quite easier than the alkylation. The product salts, however, are very reactive. $8 c$ formed may easily enter into polymerization by the contact with a small amount of the free monomer during reaction.

The reactivities of the $N$-alkylated salts $5 \mathbf{b}$ d isolated in pure form are surveyed in the middle of Table III. Each of $\mathbf{5 b}$ and $\mathbf{5 c}$ were polymerized to $6 \mathrm{~b}$ and $\mathbf{6 c}$ by both base catalyst and radical initiator. ${ }^{2,3,8}$ The polymerizability of $\mathbf{5 b}$ was relatively low because the yield and the molecular weight of the product were rather low. ${ }^{3}$ The salt $5 \mathbf{c}$ has a high radical copolymerizability with all types of vinyl monomers while 5b has no copolymerizability with electron-rich monomers. ${ }^{8}$ A salt of $\mathbf{5 d}$ has neither homopolymerizability nor copolymerizability. These differences in the reactivity would be attributed to the steric crowdedness and the electron densities around the olefinic groups. The steric hindrance is small in $\mathbf{5 c}$ with vinyl group but is the largest in $\mathbf{5 d}$ with isopropenyl group. The steric hindrance in $\mathbf{5 b}$ is partially reduced because the strained 5-membered oxazolinium ring forces the $N$-methyl group to keep away from the isopropenyl substituent. The electron-donating property of methyl substituent of isopropenyl group would also reduce the base-catalyzed polymerizability of $\mathbf{5 b}$ and $\mathbf{5 d}$.

The last column of Table III shows the reactivities of the isolated $N$-protio salts of $\mathbf{8 a}$, $\mathbf{8 b}$, and $8 \mathbf{d}$ for the base-catalyzed polymerization. The inherent reactivity of the carbon to carbon double bond of these $N$-protio salts toward nucleophile is supposed to be higher than those of the corresponding $N$-methyl salts because the steric crowdedness around double bond is smaller. The electron densities around olefinic groups are seemed similar between $N$ protio and $N$-methyl salts. 8a was polymerized with occurring proton transfer together with the usual vinyl propagation, as in the case of the "spontaneous" polymerizations of $1 \mathbf{a}$ and 1c.

8b was polymerized exclusively via protontransfer. The vinyl propagation is hampered by the steric hindrance of isopropenyl groups. $\mathbf{8 d}$ occurred no polymerize as $\mathbf{5 d}$.

From these results the order of reactivity of $N$-methyl salts is considered as $\mathbf{5 a}>\mathbf{5 c}>$ $5 \mathbf{b} \gg \mathbf{5 d}$ and that of $N$-protonated salts as $\mathbf{8 a} \cong \mathbf{8 c}>8 \mathrm{~b} \gg 8 \mathrm{~d}$. The reactivity difference can be understood consistently by their steric factors. 


\section{REFERENCES}

1. M. Miyamoto, Y. Sano, Y. Kimura, and T. Saegusa, Macromolecules, 19, 1641 (1985).

2. M. Miyamoto, Y. Sano, Y. Kimura, and T. Saegusa, submitted to Macromolecules.

3. M. Miyamoto, Y. Sano, and T. Saegusa, Makromol. Chem., 187, 1807 (1986).

4. D. A. Tomalia, B. P. Thill, and M. J. Fazio, Polym. J., 12, 661 (1980).

5. S. Kobayashi, H. Danda, and T. Saegusa,
Macromolecules, 7, 415 (1974).

6. J. C. Salamone, B. Snider, and W. L. Fitch, Macromolecules, 3, 707 (1970).

7. J. C. Salamone, A. C. Watterson, T. D. Hsu, C. C. Tsai, M. V. Mahmud, A. W. Wisniewski, and S. C. Israel, J. Polym. Sci., Polym. Symp., 64, 229 (1978).

8. M. Miyamoto, Y. Sano, and T. Saegusa, Makromol. Chem., 187, 2747 (1986).

9. S. Kobayashi and T. Saegusa, "Ring-Opening Polymerization," Vol. 2, Elsevier Applied Science Publishers, New York, N.Y., 1985, Chapter 11. 